Case Report

\title{
The Significance of ST Depression in a Postmenopausal Woman on Estrogen Therapy during Regadenoson Myocardial SPECT Imaging
}

\author{
Nishaki Kiran Mehta, Charles Hardebeck, and Martha Gulati \\ Division of Cardiovascular Medicine, The Ohio State University Wexner Medical Center, 473 West 12th Avenue, \\ Suite 200, Columbus, OH 43210, USA \\ Correspondence should be addressed to Martha Gulati; martha.gulati@osumc.edu
}

Received 16 February 2015; Accepted 31 March 2015

Academic Editor: Filippo M. Sarullo

Copyright (C) 2015 Nishaki Kiran Mehta et al. This is an open access article distributed under the Creative Commons Attribution License, which permits unrestricted use, distribution, and reproduction in any medium, provided the original work is properly cited.

\begin{abstract}
The incidence of false-positive stress tests has been noted in women, especially on hormone replacement therapy. Current literature describes this phenomenon in treadmill and adenosine stress tests. The introduction of regadenoson as a vasodilator agent has been widely adopted owing to its potency and specificity. To our knowledge, false-positive stress test with regadenoson in a postmenopausal woman on estrogen has never been described. Given the higher chronotropic response with regadenoson, we believe that normal perfusion images with a higher heart rate response indicate a good prognosis in such patients.
\end{abstract}

\section{Introduction}

Whereas mild-to-moderate ST changes in the presence of normal single photon emission computed tomography (SPECT) images (+EKG/-SPECT) during exercise is generally considered a "false-positive" EKG response and thus a low-risk pattern, the diagnostic and prognostic significance of this combination during vasodilator stress is more controversial [1-8]. While +EKG/-SPECT during vasodilator stress likely represents benign (nonischemic) finding in many patients, elevated rates of cardiac events or revascularization have been noted in association with elevated baseline risk (established coronary disease, diabetics, and elderly patients) $[3,4,7]$; recent commentaries have thus recommended that decisions regarding additional testing in this circumstance consider the full clinical context leading to the exam $[2,6]$.

Published analyses of + EKG/-SPECT with vasodilator stress note a predominance in female patients $(77-88 \%)$ of postmenopausal age (mean age 65-72) [3-5, 7, 8]. Although these studies excluded certain patients likely to have stressinduced ST changes unassociated with coronary disease (LBBB, resting ST changes, and digoxin therapy), possible association with estrogen replacement therapy (ERT) was generally not considered (one study noted ERT in 7/43 woman patients with +EKG/-SPECT) [3]. ERT is a wellestablished contributor to nonischemic ST changes during exercise stress testing $[9,10]$. As chronotropic response to vasodilator stress in normal individuals is relatively brisk (particularly with regadenoson) [11], the electrocardiographic response during ERT may therefore mimic that observed during exercise.

\section{Case Report}

A 60-year-old postmenopausal Caucasian woman with history of hypertension and hyperlipidemia was referred for myocardial SPECT exam with pharmacologic stress (regadenoson $0.4 \mathrm{mg}$ ) for evaluation of atypical angina. The patient was noted to be taking chronic ERT (conjugated estrogen $0.625 \mathrm{mg}$ per day). Baseline EKG revealed normal sinus rhythm with no significant ST changes (Figure 1(a)). Following regadenoson administration, she developed $1.5 \mathrm{~mm}$ inferolateral ST depression (Figure 1). Stress and rest SPECT images revealed normal perfusion patterns (Figure 2), with normal left ventricular systolic function on gated images (LVEF 65\%). Because of ongoing symptoms and persistent 


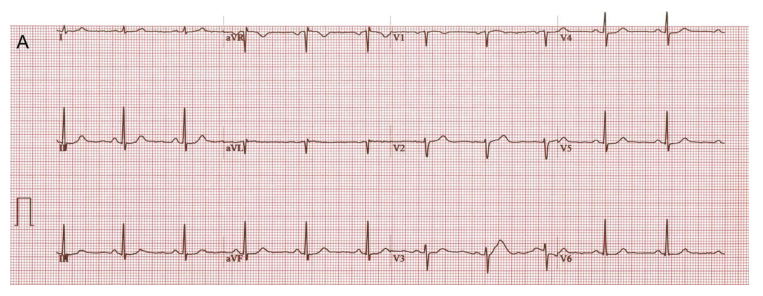

(a)

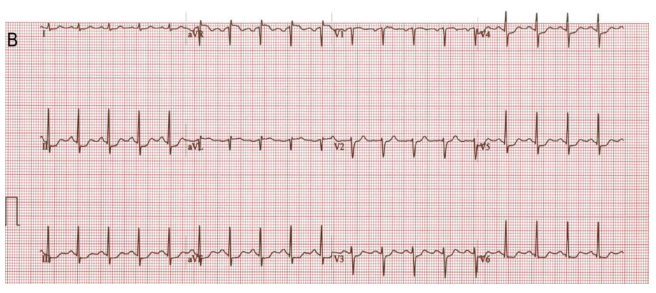

(b)

FIGURE 1: Resting (a) and stress (b) EKG tracings on patient undergoing regadenoson SPECT exam while taking chronic conjugated estrogen therapy. With pharmacologic stress, the patient developed $1.5 \mathrm{~mm}$ ST depression in the inferolateral distribution at a heart rate change of 50 (resting heart rate 61, peak stress heart rate $116, \Delta \mathrm{ST} / \Delta \mathrm{HR}=2$ ).

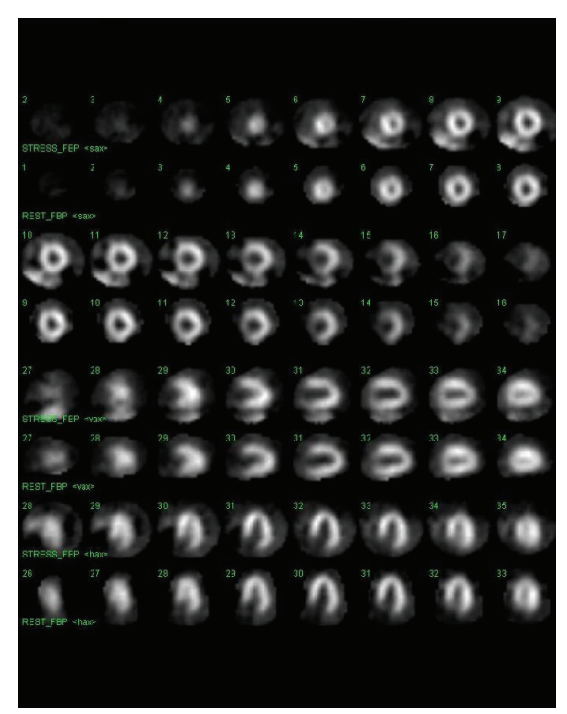

FIGURE 2: Gray scale stress (top panels) and rest (bottom panels) perfusion images, revealing absence of perfusion abnormality.

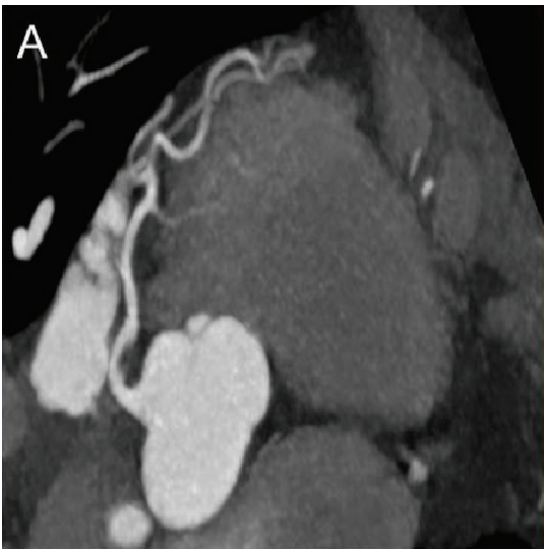

(a)

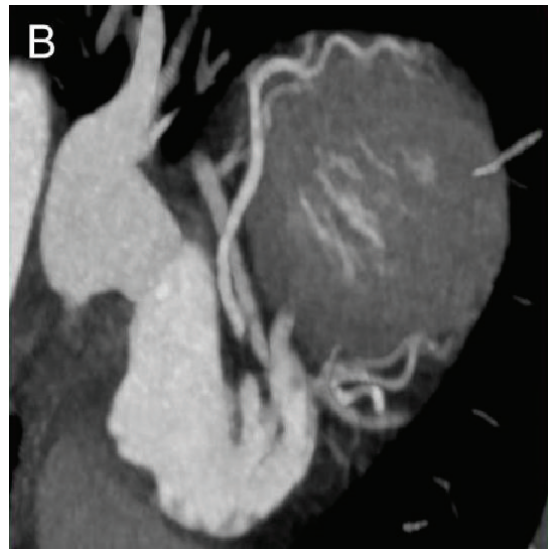

(b)

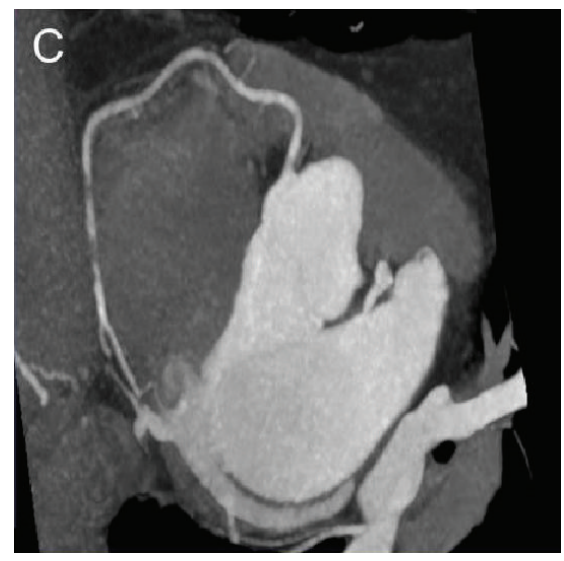

(c)

FIGURE 3: Coronary computed tomography showing absence of coronary artery calcium, with no evidence of arteriosclerotic disease.

concern regarding cardiac risk, she underwent follow-up coronary computed tomography angiography with calcium scoring which revealed absence of coronary calcification or disease (Figure 3).

\section{Discussion}

To our knowledge, the occurrence of "false-positive" vasodilator EKG response associated with ERT and regadenoson is previously unreported. The case illustrates the importance of specific review and documentation of concomitant drug therapy (particularly ERT), in addition to cardiovascular risk factors when evaluating the significance of +EKG/-SPECT during pharmacologic stress. As ST depression associated with ERT use is rate-dependent, and a brisk chronotropic response to vasodilator stress (seen with regadenoson) is considered a favorable prognostic indicator [12], the latter in 
association with +EKG/-SPECT in patients on ERT would likely indicate a low-risk pattern.

Female-specific ischemic heart disease, erstwhile referred to as cardiac syndrome X, is associated with ST changes with exercise $[13,14]$. Although this remained on the differential, our patient had pharmacologic agent-induced ECG changes, and not exercise-induced ECG changes, which made the likelihood of false-positive with ERT more likely.

\section{Conflict of Interests}

The authors declare that there is no conflict of interests regarding the publication of this paper.

\section{Acknowledgment}

The authors would like to thank Jason Craft M.D. for his help with the CT images.

\section{References}

[1] R. Hachamovitch, D. S. Berman, H. Kiat et al., "Exercise myocardial perfusion SPECT in patients without known coronary artery disease: incremental prognostic value and use in risk stratification," Circulation, vol. 93, no. 5, pp. 905-914, 1996.

[2] B. G. Abbott, "The vasodilator stress ECG: should depression cause anxiety?" Journal of Nuclear Cardiology, vol. 19, no. 1, pp. 13-15, 2012.

[3] E. Klodas, T. D. Miller, T. F. Christian, D. O. Hodge, and R. J. Gibbons, "Prognostic significance of ischemic electrocardiographic changes during vasodilator stress testing in patients with normal SPECT images," Journal of Nuclear Cardiology, vol. 10, no. 1, pp. 4-8, 2003.

[4] S. Uthamalingam, G. S. Gurm, I. Ahmado, M. S. Sidhu, and J. Flynn, "Outcome of patients with regadenoson-induced STsegment depression but normal perfusion on single-photon emission computed tomography," Angiology, vol. 64, no. 1, pp. 46-48, 2013.

[5] J. Sharma, C. Roncari, K. N. Giedd, J. T. Fox, and Y. Kanei, "Patients with adenosine-induced ST-segment depressions and normal myocardial perfusion imaging: cardiac outcomes at 24 months," Journal of Nuclear Cardiology, vol. 17, no. 5, pp. 874$880,2010$.

[6] S. Dahlberg and J. Leppo, "Risk stratification of the normal perfusion scan: does normal stress perfusion always mean very low risk?" Journal of Nuclear Cardiology, vol. 10, no. 1, pp. 87-91, 2003.

[7] B. G. Abbott, M. Afshar, A. K. Berger, and F. J. T. Wackers, "Prognostic significance of ischemic electrocardiographic changes during adenosine infusion in patients with normal myocardial perfusion imaging," Journal of Nuclear Cardiology, vol. 10, no. 1, pp. 9-16, 2003.

[8] F. G. Hage, E. V. Dubovsky, J. Heo, and A. E. Iskandrian, "Outcome of patients with adenosine-induced ST-segment depression but with normal perfusion on tomographic imaging," American Journal of Cardiology, vol. 98, no. 8, pp. 10091011, 2006.

[9] M. J. Henzlova, L. B. Croft, and J. A. Diamond, "Effect of hormone replacement therapy on the electrocardiographic response to exercise," Journal of Nuclear Cardiology, vol. 9, no. 4, pp. 385-387, 2002.
[10] A. P. Morise and R. Beto, "The specificity of exercise electrocardiography in women grouped by estrogen status," International Journal of Cardiology, vol. 60, no. 1, pp. 55-65, 1997.

[11] S. Vasu, W. P. Bandettini, L.-Y. Hsu et al., "Regadenoson and adenosine are equivalent vasodilators and are superior than dipyridamole- a study of first pass quantitative perfusion cardiovascular magnetic resonance," Journal of Cardiovascular Magnetic Resonance, vol. 15, article 85, 2013.

[12] A. Abidov, R. Hachamovitch, S. W. Hayes et al., "Prognostic impact of hemodynamic response to adenosine in patients older than age 55 years undergoing vasodilator stress myocardial perfusion study," Circulation, vol. 107, no. 23, pp. 2894-2899, 2003.

[13] J. H. Mieres, M. Gulati, N. B. Merz et al., "Role of noninvasive testing in the clinical evaluation of women with suspected ischemic heart disease: a consensus statement from the American Heart Association," Circulation, vol. 130, no. 4, pp. 350-379, 2014.

[14] M. Gulati, L. J. Shaw, and C. N. Bairey Merz, "Myocardial ischemia in women: lessons from the NHLBI WISE study," Clinical Cardiology, vol. 35, no. 3, pp. 141-148, 2012. 


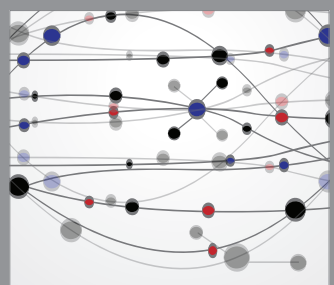

The Scientific World Journal
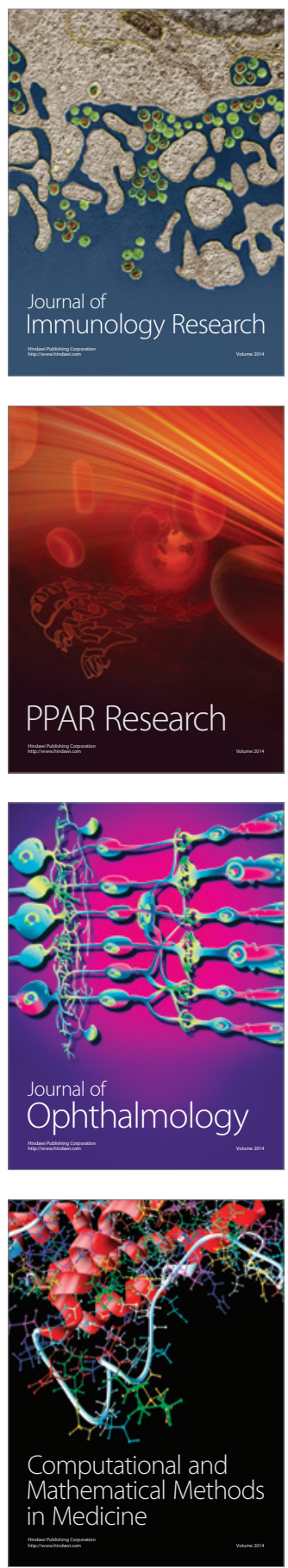

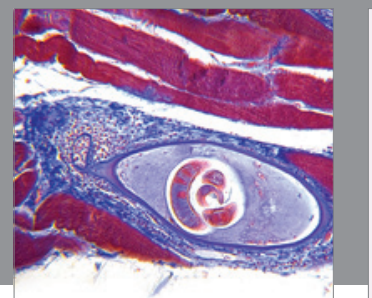

Gastroenterology

Research and Practice
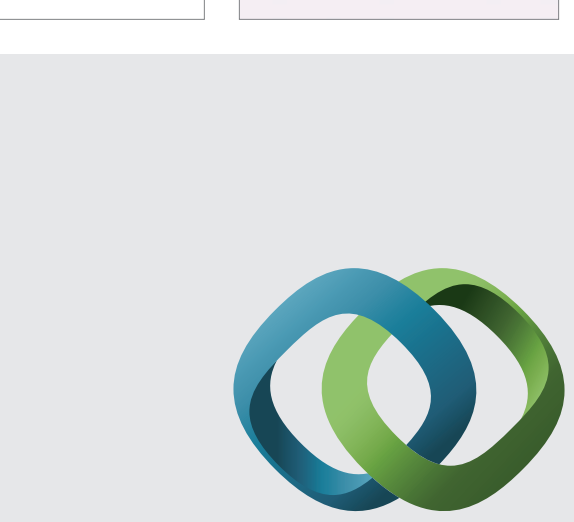

\section{Hindawi}

Submit your manuscripts at

http://www.hindawi.com
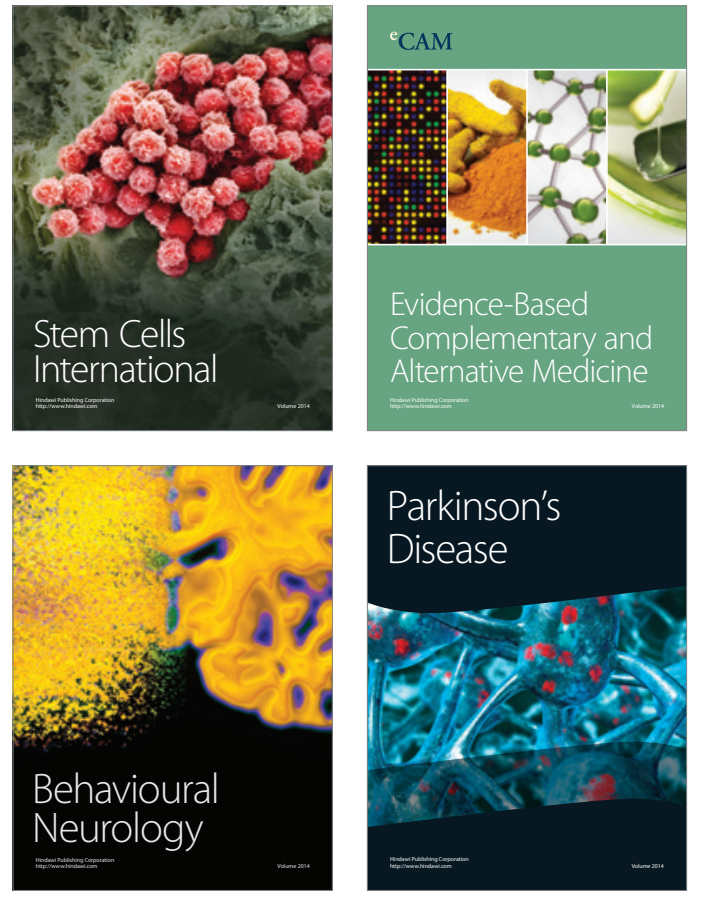
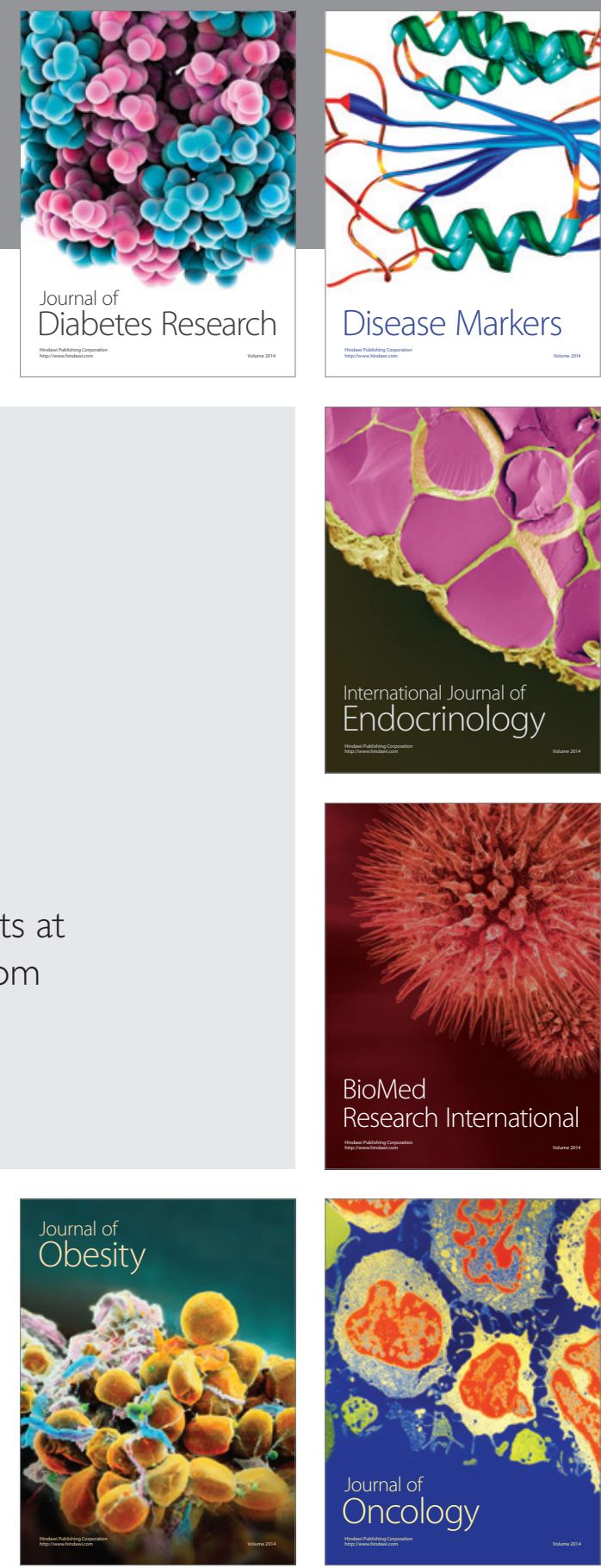

Disease Markers
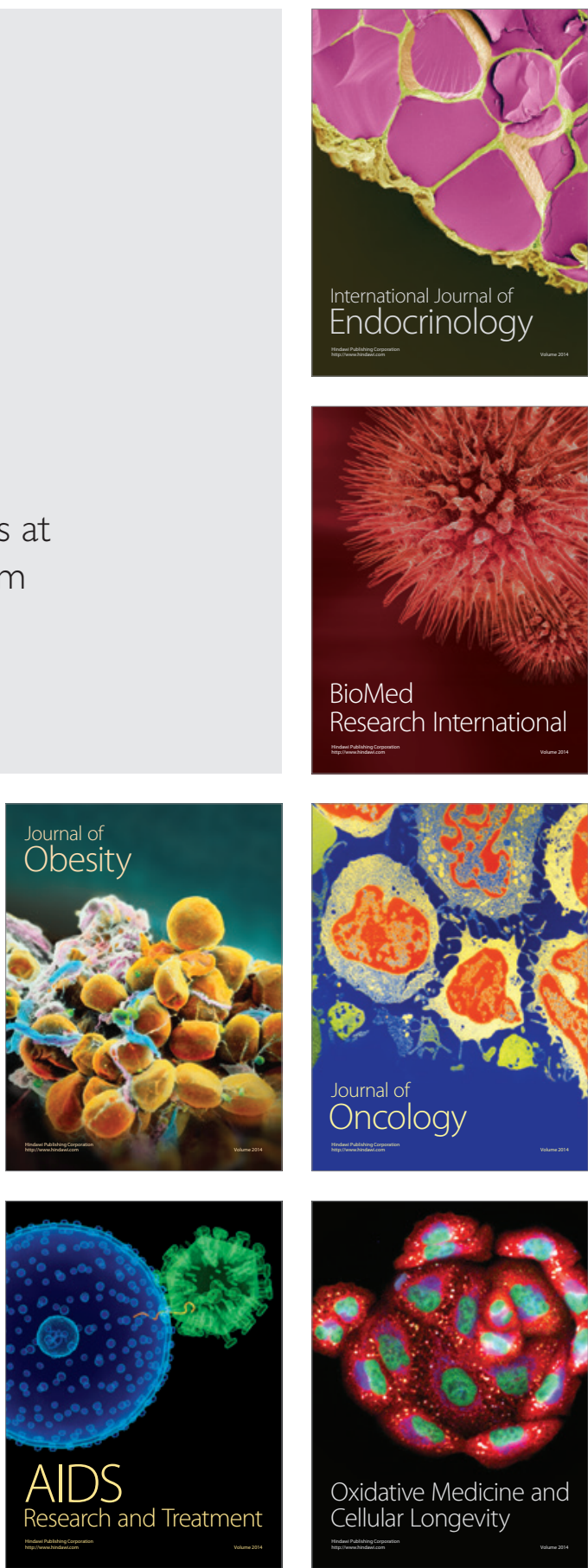